\title{
Evaluation of the growth traits of Toxicodendron vernicifluum progeny based on their genetic groups assigned using new microsatellite markers
}

\author{
By Y. HiraOKA $\left.{ }^{*}, 1\right)$, S. HANAOKA ${ }^{1)}$, A. WATANABE ${ }^{2)}$, T. KaWAHARA $^{3)}$ and M. TABATA ${ }^{4)}$
}

(Received $6^{\text {th }}$ June 2014)

\begin{abstract}
Toxicodendron vernicifluum (Stokes) F. A. Barkley is a tree species cultivated in Japan for production of Japanese lacquer. To facilitate the low-cost improvement of T. vernicifluum, we developed microsatellite markers for DNA fingerprinting and family and lineage reconstruction. Nine useful microsatellites were developed, with 3 to 23 alleles per locus and an expected heterozygosity of $0.162-0.838$ based on a commercially planted population that included 783 offspring. Six clusters were detected in this population based on the Bayesian clustering method, and 93 half-sib families were identified using parentage and sibship assignment analysis based on a maximum likelihood method. Many members (40-96\%) of large ( $\geq 10)$ half-sib families included specific clusters, and members from different families included the same clusters. The cluster effect for tree height was more significant than the half-sib family effect using a linear mixed model, although these effects were not significant for other traits (diameter at breast height and number of forked trunks). Based on the findings from pedigree reconstruction, backward selection for tree height seems possible. We discuss the direction of research for improving T. vernicifluum using our proposed approach.
\end{abstract}

Key words: Backward selection; Bayesian clustering; Best unbiased linear predictor; Microsatellite; Pedigree reconstruction; Toxicodendron vernicifluum (Stokes) F.A. Barkley.

\section{Introduction}

Toxicodendron vernicifluum (Stokes) F.A. Barkley (lacquer tree) is a deciduous, dioecious tree of the family Anacardiaceae that is widely distributed in China and India (IwATSUKI, 1999). In Japan, the sap of this species has been used to produce Japanese lacquer for at least 6,500 years. In addition to the production of lacquer sap, a raw material for manufacturing lacquerware, the tree has economic and cultural importance for other uses, including repairing cultural property such as traditional Shinto shrines and Buddhist temples (MіYAмото and KAKUDA, 2008).

To enhance the production of Japanese lacquer, genetic improvement of this species is needed. Despite its

\footnotetext{
1) Forest Tree Breeding Center, Forestry and Forest Products Research Institute (FFPRI), 3809-1 Ishi, Juo, Hitachi, Ibaraki 319-1301, Japan.

2) Faculty of Agriculture, Kyushu University, Hakozaki 6-10-1, Higashiku, Fukuoka, 812-8581, Japan.

3) FFPRI, 1 Matsunosato, Tsukuba, Ibaraki, 305-8687, Japan.

4) 92-25 Nabeyashiki, Shimokuriyagawa, Morioka, Iwate, 0200123, Japan.

*) Corresponding author: Yuichiro HiRaOKA. Tel. +81-294-39-7000, Fax. +81-294-39-7306. E-Mail: yhiraoka@affrc.go.jp
}

long history of cultivation, no improvement programs exist for $T$. vernicifluum, although in some regions, seedlings derived from superior female trees or clones propagated from roots of superior trees have been planted. Conventionally, many forest tree improvement programs have been started with selection of plus trees, which requires significant effort, cost, and time. Recently, family reconstruction based on paternal analysis using DNA markers has become a practical method for forest tree improvement, called breeding with paternal analysis in an open-pollinated progeny test or polymix breeding with parental analysis (GRATTAPAGLIA et al., 2004; LAMBETH et al., 2001; MoRIGUCHI et al., 2011). ELKASSABY and LSTIBŮREK (2009) proposed so-called breeding without breeding ( $\mathrm{BwB})$, which is a breeding with paternal analysis approach for backward and forward selection in an open-pollinated progeny test. The method combines the use of genotypic or phenotypic preselection of superior individuals, informative DNA markers for fingerprinting, and pedigree reconstruction of offspring to assemble naturally created full- and half-sib families from selected parents, and uses quantitative genetics to identify elite genotypes for further improvement or establishment of production populations (EL-KASSABY and LSTIBŮREK, 2009). The method's simplicity offers an exceptional opportunity for the development of comparable breeding efforts in developing countries, in advanced and new breeding programs, and for both economically important and minor species (EL-KASSABY and LSTIBŮREK, 2009). Thus, BwB approaches are also considered very effective for non-breeding tree species such as T. vernicifluum, because of the lack of both paternal and maternal information as well as a progeny test site designed for tree improvement.

Appropriate co-dominant DNA markers such as microsatellites have not been previously developed for T. vernicifluum, although microsatellites for related species such as T. succedaneum (or Rhus succedanea) have (HIRAOKA and WATANABE, 2010), but were not suitable for T. vernicifluum (T. Tanaka, personal communication). Therefore, it was necessary to develop co-dominant DNA markers to use a family reconstruction approach for this species.

The objectives of this study were (1) to develop microsatellite markers for T. vernicifluum; (2) to estimate family or lineage (i.e., genetic group) in an openpollinated progeny forest of this species based on multilocus genotype data; and (3) to evaluate the suitability of backward selection for growth and tree-form traits using the genetic information derived from the microsatellites. 


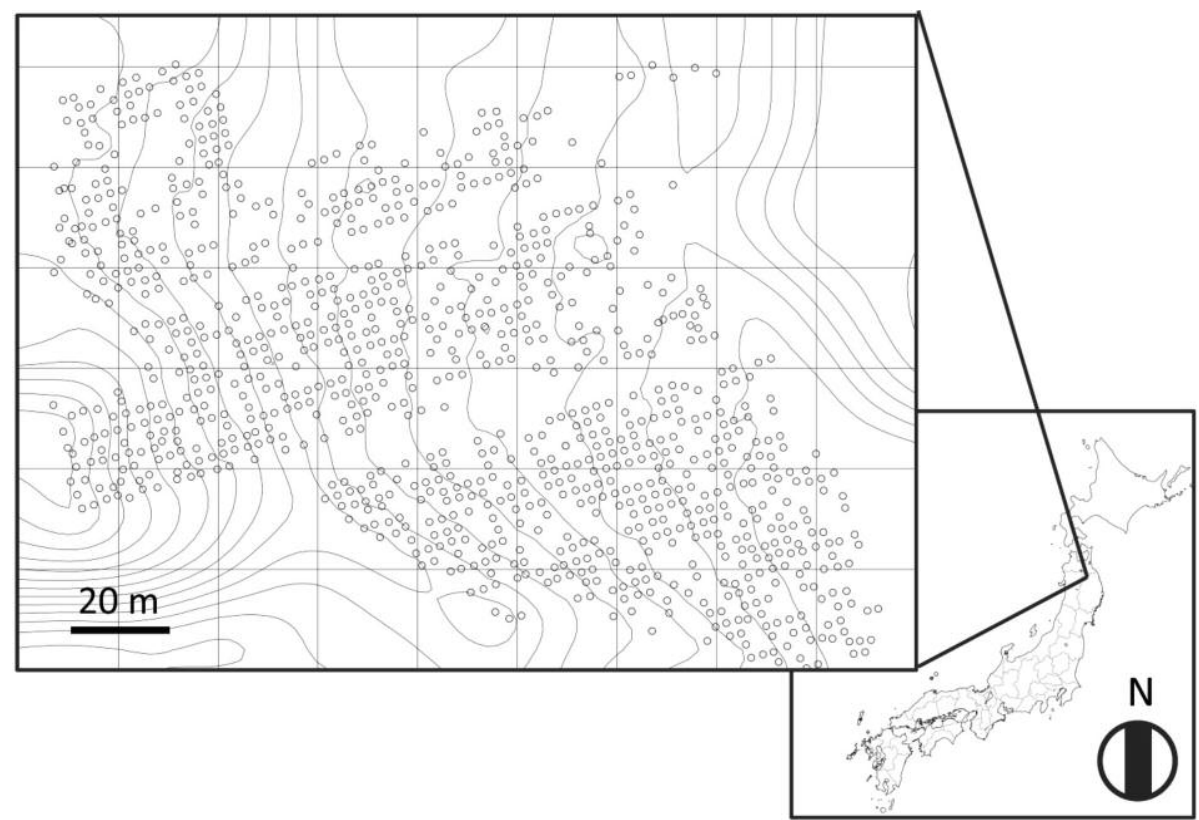

Figure 1. - Location of the study site. The circles represent the individuals surviving in 2011.

\section{Materials and Methods}

\section{Study site and plant materials}

Our study site (1.6 ha) is located in Joboji, Ninohe City, Iwate, Japan (Fig. 1; lat. N $40^{\circ} 11^{\prime}$, long. E $141^{\circ} 7$ ', altitude ca. $300 \mathrm{~m}$ above sea level). This region is the largest production center of $T$. vernicifluum seedlings, accounting for about $80 \%$ of the production volume of Japan. The mean annual temperature is $8.3^{\circ} \mathrm{C}$, and the mean annual rainfall is $1,346 \mathrm{~mm}$, as noted in Mesh Climate Data 2000 (Japan Meteorological AGENCy, 2002). About 900 seedlings were planted in 1988 that were derived from an unknown number of female trees; therefore, there is no information about the genetic identity of the seedlings. The field assessments were carried out in 2011. For each individual, tree height (m), maximum trunk diameter at breast height (DBH, in $\mathrm{cm}$ ), and fork number (number of forked trunks) were recorded.

Fresh leaves were collected from 783 living individuals in the progeny forest for DNA extraction. Total genomic DNA was extracted using a modified hexadecyltrimethylammonium bromide method (SHIRAISHI and WATANABE, 1995).

\section{Microsatellite development and evaluation}

Microsatellite loci were isolated using the enrichment method described in HAMILTON et al. (1999). DNA was extracted from an individual, and approximately $1 \mu \mathrm{g}$ of DNA was digested with EcoR V (Promega) at $37^{\circ} \mathrm{C}$ for 2 hours. The 21-mer and 25-mer nucleotide linkers 5'-CTCTTGCTTACGCGTGGACTA-3' and 5'-TAGTCCACGCGTAAGCAAGCAAGAGCACA-3' were ligated to both ends of digested fragments using the TAKARA ligation kit ver. 2.1 (Takara). Ligated fragments were hybridized with biotinylated $(\mathrm{CA})_{10}$ and $(\mathrm{GA})_{10}$ oligonucleotides and were captured using Dynabeads streptavidin-coated magnetic beads (Dynal). Enriched DNA fragments were recovered by denaturation and subsequently amplified in a polymerase chain reaction (PCR) using the 21-mer linker as a primer. The PCR products were purified using a QIAquick PCR Purification Kit (QIAGEN) and were cloned using PT7 Blue T-vector (Novagen). Clones obtained by blue/white selection were sequenced using a BigDye Terminator Cycle Sequencing Kit ver. 3.1 with universal T7 or U19 primers and an ABI 3130xl sequencer (Applied Biosystems). Sequences that included simple sequence repeats with more than four repeats were selected, and primers were designed using Primer3Plus (UnTERGASSER et al., 2012; http://www.bioinformatics.nl/cgi-bin/primer3plus/ primer3plus.cgi/; accessed December 17, 2013). After optimization, PCR was performed in mixtures with a final volume of $10 \mu$ l containing $1 \times$ QIAGEN Multiplex PCR Master Mix (QIAGEN), 0.1-0.5 $\mu \mathrm{M}$ FAM-, NED-, VIC-, or PET-labeled forward primer and reverse primer and $25 \mathrm{ng}$ template DNA. PCR was carried out using a PTC-200 thermal cycler (MJ Research) with the following profile: (i) an initial denaturation step of $1 \mathrm{~min}$ at $95^{\circ} \mathrm{C}$, (ii) a touchdown PCR sequence consisting of 10 cycles of $95^{\circ} \mathrm{C}$ for $30 \mathrm{~s}, 60^{\circ} \mathrm{C}$ to $50^{\circ} \mathrm{C}$ for $90 \mathrm{~s}$ (decreasing by $1{ }^{\circ} \mathrm{C} /$ cycle), and $72^{\circ} \mathrm{C}$ for $60 \mathrm{~s} ; 20$ cycles at $95^{\circ} \mathrm{C}$ for $30 \mathrm{~s}, 50^{\circ} \mathrm{C}$ for $90 \mathrm{~s}$, and $72^{\circ} \mathrm{C}$ for $60 \mathrm{~s}$ and (iii) a final extension of $30 \mathrm{~min}$ at $60^{\circ} \mathrm{C}$. Amplified PCR products were sequenced, again using an ABI 3130xl sequencer. GeneMapper software (Applied Biosystems) was used to determine fragment sizes and to analyze the results. All loci were genotyped and variable loci with clear peaks were selected. To assess the informative potential of the 
microsatellites, observed $\left(\mathrm{H}_{\mathrm{O}}\right)$ and expected $\left(\mathrm{H}_{\mathrm{E}}\right)$ heterozygosity were calculated based on the genotype data obtained from each primer pair by Cervus 2.0 software (MARSHALl et al., 1998).

\section{Data analysis}

In this study, we conducted two different approaches to detect genetic groups. First, the Bayesian clustering method was used to elucidate the genetic structure using STRUCTURE ver. 2.3.4 software (PRITCHARD et al., 2000). This program implements a model-based clustering method for inferring population structure using genotype data, based on providing a group membership posterior probability of individuals. The model applied in the analysis assumes the existence of $K$ clusters, yields estimates of the number of clusters, and assigns individuals to one or more clusters through Markov chain Monte Carlo simulation. It is possible that the population of open-pollinated offspring has multiple hierarchical genetic structures, such as one structure among parents and one within families. In order to determine the appropriate cluster for such a population, hierarchical structure analysis (VÄHÄ et al., 2007) was applied in this study. This approach aims for the smallest value of $K$ that captures the major structure in the data at first, and subsequently determines structure on partitioned data (PRITCHARD and WEN, 2004). To determine the correct value of $K$, we applied the maximal $\Delta K$, the change in $\ln P(X \mid K)$ between successive $K$ values (EvANNo et al., 2005). Each individual was assumed to belong to any cluster showing the maximum $q$ value. Simulations were run 10 times for each value of $K$ (from 1 to 10 ) for $10^{5}$ iterations after a burn-in period of $10^{4}$. Second, the COLONY2 program (WANG, 2004;

Table 1. - Locus names, repeat motifs of cloned alleles and primer sequences of the microsatellite loci.

\begin{tabular}{|c|c|c|}
\hline Locus & Repeat motif & Primer sequences $\left(5^{x}-3^{x}\right)$ \\
\hline betvo03 & $(\mathrm{TC})_{12}$ & F: CTCACAACTGTCCACCACAA \\
\hline & & R: TCGGGATTACAAGGGTGATA \\
\hline betvo0 05 & $(\mathrm{TC})_{12}$ & $\begin{array}{l}\text { F: CACCATTTCCCCTTTCTAGC } \\
\text { R: CCTGGCCAGATATTAAAGCA }\end{array}$ \\
\hline betvo0 07 & $(\mathrm{TG})_{1+}$ & $\begin{array}{l}\text { F: CCAGTATCAGGTAAAGCAAAGAG } \\
\text { R: GGGACCCATGTATGTTGTGA }\end{array}$ \\
\hline betvolu & $(\mathrm{TC})_{17}$ & $\begin{array}{l}\text { F: CACCCCAACACTACTCGCTAA } \\
\text { R: TGGATGTCATTACCOCAACT }\end{array}$ \\
\hline betwo19 & $(\mathrm{CT})_{6} \mathrm{CA}(\mathrm{CT})_{9}$ & $\begin{array}{l}\text { F: AAATCCAACGGCTCACATTC } \\
\text { R: TTTGAATCGCACTGGTGTTC }\end{array}$ \\
\hline betv 024 & $(\mathrm{TC})_{2,3}$ & $\begin{array}{l}\text { F: TGCATACATCAGAAAATAATGTGC } \\
\text { R: ACGATCCTTT TGCATCACAAC }\end{array}$ \\
\hline betvo 45 & $(\mathrm{GA})_{21}$ & $\begin{array}{l}\text { F: GGCCTCTGGTTTCTATTACCA } \\
\text { R: GAAGGCCAATGAATGCTC }\end{array}$ \\
\hline betv0 055 & $(\mathrm{TC})_{14} \mathrm{TT}(\mathrm{TC})_{12}$ & $\begin{array}{l}\text { F: CCCCACTAATAGACAAAAGGAAA } \\
\text { R: TCAGAAGTCGTAATGTTACCTCAGA }\end{array}$ \\
\hline betvo60 & $(\mathrm{CT})_{5}$ TTAT $(\mathrm{CT})_{12}$ & $\begin{array}{l}\text { F: TTTGTTTAATCCACACTCCTCTCTC } \\
\text { R: CGTGGAAACTCTGCACAATC }\end{array}$ \\
\hline
\end{tabular}

Table 2. - Allele diversity and observed $\left(\mathrm{H}_{\mathrm{O}}\right)$ and expected $\left(\mathrm{H}_{\mathrm{E}}\right)$ heterozygosity (MARSHALl et al., 1998) based on the 769 different genotypes.

\begin{tabular}{llclll}
\hline Locus & Range & No. of & \multicolumn{1}{l}{$\mathrm{H}_{\mathrm{O}}$} & $\mathrm{H}_{\mathrm{E}}$ & GenBank \\
& (bp) & Alleles & & & Accession no. \\
\hline bctv003 & $205-219$ & 5 & 0.647 & 0.542 & AB921288 \\
betv005 & $162-168$ & 4 & 0.617 & 0.587 & AB921289 \\
betv007 & $135-151$ & 3 & 0.164 & 0.162 & AB921290 \\
betv014 & $146-172$ & 12 & 0.782 & 0.782 & AB921291 \\
bctv019 & $202-208$ & 3 & 0.273 & 0.269 & AB921292 \\
bctv024 & $130-187$ & 23 & 0.840 & 0.838 & AB921293 \\
bctv045 & $204-234$ & 11 & 0.577 & 0.573 & AB921294 \\
bctv055 & $164-233$ & 20 & 0.747 & 0.761 & AB921295 \\
bctv060 & $156-170$ & 6 & 0.288 & 0.280 & AB921296 \\
\hline
\end{tabular}




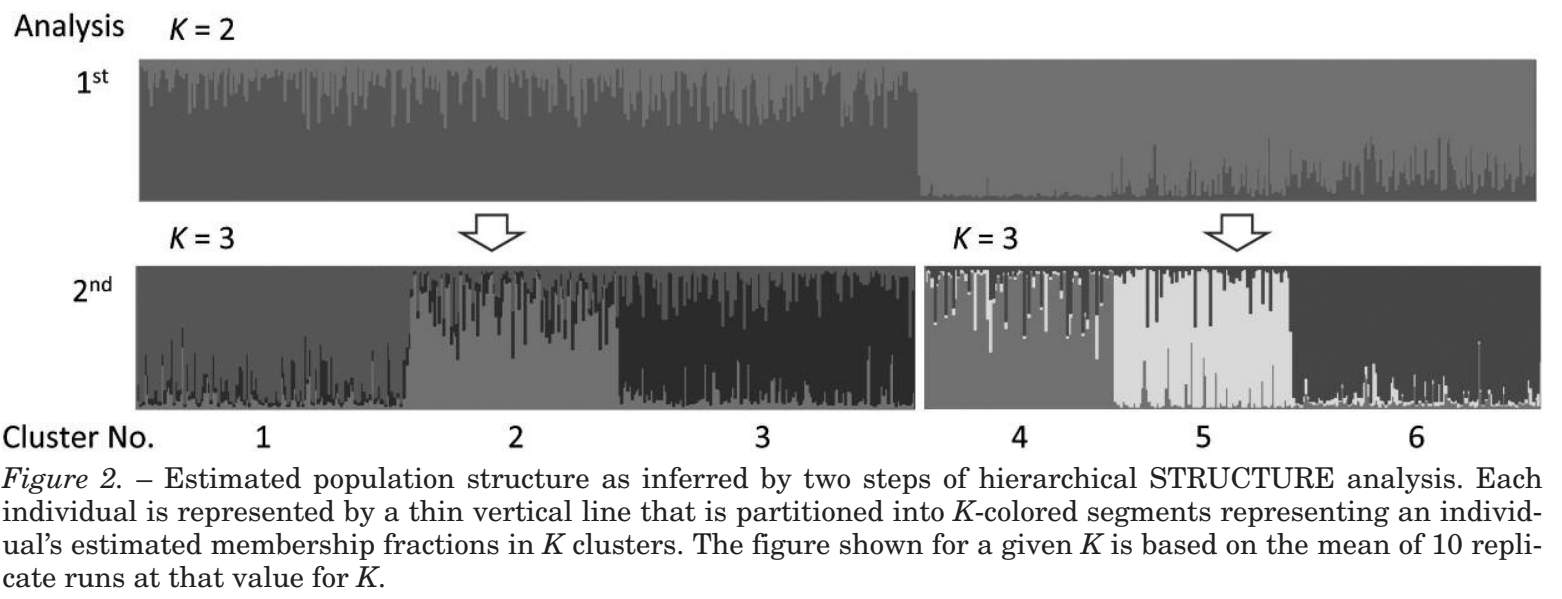

WANG and SANTURE, 2009; Jones and WANG, 2010) was used to reconstruct the pedigrees of all individuals by applying their genotype data. This program implements a maximum likelihood method to assign an inferred parentage and sibship among offspring using their multilocus genotypes. The settings of the program were based on the following assumptions: 1) seed donors received pollen from multiple male parents in their vicinity (i.e., mother trees were polygamous) and 2) selffertilization did not occur because this species is dioecious. Each genotyping error rate was set at $1 \%$.

We carried out backward selection for growth and tree-form traits using the linear mixed model, including the factor of genetic information derived from STRUCTURE and COLONY analyses. The best linear unbiased predictor (BLUP) scores for height, $\mathrm{DBH}$, and fork number were calculated using ASReml 3.0 software (GILMOUR et al., 2009). The following linear mixed models were used to describe the observed values, including fixed and random factors, appropriate for the mixed model methodology:

$$
\begin{aligned}
& y_{i j}=\mu+C_{j}+e_{i j} \text { (Eq. 1) } \\
& y_{i j}=\mu+F_{j}+e_{i j} \text { (Eq. 2) }
\end{aligned}
$$

where $y$ represents the observation for the target trait of each individual, $\mu$ represents the general mean, $C_{j}$ represents the random effect of cluster $j$ based on STRUCTURE analysis, and $F_{j}$ represent the random effect of female $j$ based on COLONY analysis. The $e$ factor is the residual; the vector of residuals is assumed to be fit a spatial model, as $e=\zeta+\eta$, where $\zeta$ is the vector of spatially dependent residuals and $\eta$ is the vector of spatially independent residuals. We used a separable firstorder autoregressive process $(\mathrm{AR} 1 \otimes \mathrm{AR} 1)$ to model the covariance structure of $\zeta$, since Gilmour et al. (1997) suggested that this spatial method is often useful. The form of the $\mathbf{R}$ matrix is given by DuTKOWSKI et al. (2002):

$$
\mathbf{R}=\sigma_{\zeta}^{2}\left[\operatorname{AR}\left(\rho_{\text {col }}\right) \otimes \operatorname{AR} 1\left(\rho_{\text {row }}\right)\right]+\sigma_{\eta}^{2} \mathbf{I},
$$

where $\operatorname{AR}\left(\rho_{\text {col }}\right)$ and $\operatorname{AR} 1\left(\rho_{\text {row }}\right)$ represent first-order autoregressive correlation matrices for columns and rows, respectively, and $\sigma_{\zeta}^{2}$ and $\sigma_{\eta}^{2}$ are the spatial and nonspatial residual variances, respectively. The symbol $\otimes$ is the Kronecker product. Eqs. 1 and 2 will be called the STRUCTURE model and COLONY model, respectively. Goodness of fit of the estimated models was assessed based on Akaike's information criterion (AIC, AKAIKE, 1974):

$$
\mathrm{AIC}=-2 \log L+2 d,
$$

where $d$ is the number of parameters estimated and $\log L$ is the $\log$-likelihood for the estimated model. A smaller AIC value represents a better model fit. A likelihood ratio test according to SELF and LIANG (1987) was employed for comparison with no genetic factor models.

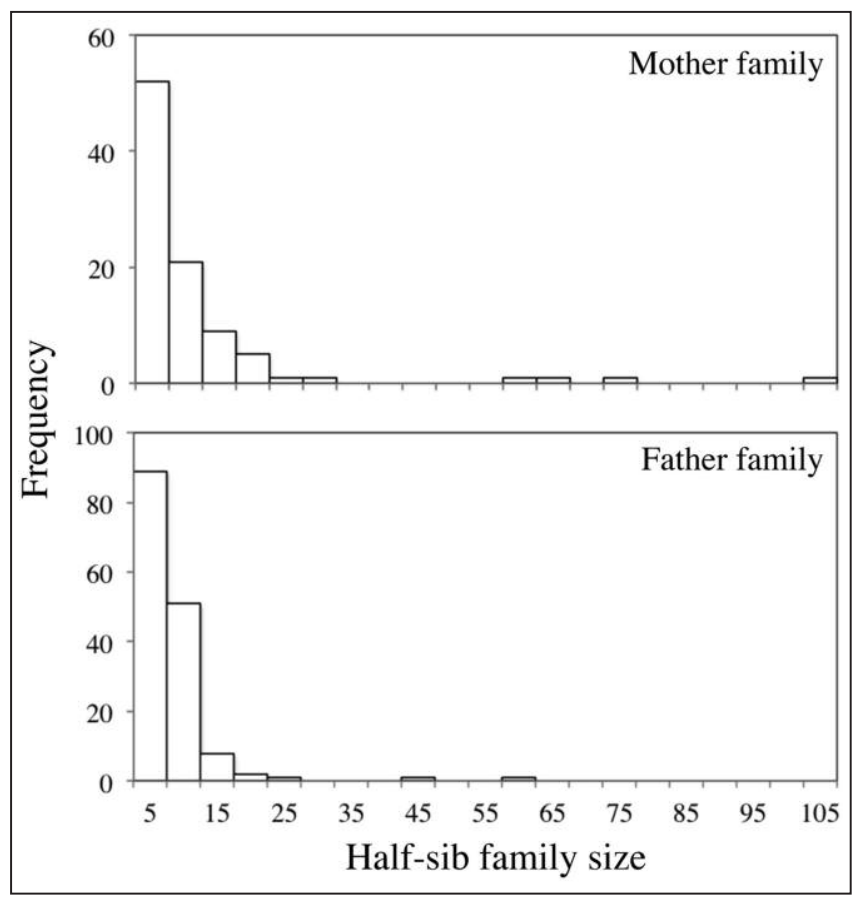

Figure 3. - The frequency distribution of maternal family size estimated by the COLONY program. 


\section{Results}

Development and characterization of microsatellite markers and identification of genotypes

Of 480 clones sequenced, 176 included a simple sequence repeat with more than four repeats; 117 primers were designed based on these sequences. These primers were tested on eight individuals, and nine primer pairs were considered useful because they generated one or two bands for each genotype and suggested the detection of a single locus (Table 1).

Using the nine microsatellite markers, DNA samples from 783 individuals were amplified by PCR, with 769 different genotypes detected. Allelic diversity and heterozygosity are shown in Table 2 . The number of alleles per locus ranged from 3 to 23 (mean $\pm \mathrm{SD}=9.67 \pm 7.06)$.
The calculated observed $\left(\mathrm{H}_{\mathrm{O}}\right)$ and expected $\left(\mathrm{H}_{\mathrm{E}}\right)$ heterozygosity based on all of the genotypes varied respectively between 0.164 and $0.840(0.55 \pm 0.23)$ and between 0.162 and $0.838(0.53 \pm 0.23)$.

\section{Classification of genetic groups based on microsatellite marker data}

In the first step of STRUCTURE analysis, the values of $\Delta K$, which based on the rate of change of $\ln P(X \mid K)$ between successive $K$ values, were highest at $K=2$. Therefore, the population was divided into two groups. In the second step, both groups showed the highest $\Delta K$ values at $K=3$, thus, each group was separated into three clusters. As a result, six clusters were detected from STRUCTURE analysis (Fig. 2). The COLONY program was used for pedigree reconstruction, leading to

Table 3. - The number of half-sib offspring for each cluster.

\begin{tabular}{|c|c|c|c|c|c|c|c|c|}
\hline \multirow[t]{2}{*}{ Mother } & \multicolumn{6}{|c|}{ Cluster No. } & \multirow[b]{2}{*}{ Total } & \multirow[b]{2}{*}{$\%^{\circ}$} \\
\hline & 1 & 2 & 3 & 4 & 5 & 6 & & \\
\hline$\# 8$ & 3 & 1 & 10 & 49 & 2 & 39 & 104 & 47.1 \\
\hline$\# 6$ & & & 3 & & 70 & & 73 & 95.9 \\
\hline$\# 1$ & 58 & 1 & 1 & 1 & & & 61 & 95.1 \\
\hline$\# 3$ & 1 & 54 & 3 & & 1 & & 59 & 91.5 \\
\hline$\# 38$ & & 1 & 3 & 4 & & 19 & 27 & 70.4 \\
\hline \#19 & & 3 & 4 & 4 & 10 & 1 & 22 & 45.5 \\
\hline$\# 15$ & 1 & 1 & 5 & 1 & & 9 & 17 & 52.9 \\
\hline$\# 25$ & & 1 & 3 & 5 & & 7 & 16 & 43.8 \\
\hline$\# 36$ & 1 & 2 & I & 1 & 10 & 1 & 16 & 62.5 \\
\hline$\# 11$ & & & 3 & 4 & 1 & 7 & 15 & 46.7 \\
\hline \#21 & & & 6 & & & 9 & 15 & 60.0 \\
\hline$\# 24$ & & & 4 & 4 & & 6 & 14 & 42.9 \\
\hline$\# 10$ & & 5 & 8 & & & & 13 & 61.5 \\
\hline$\# 46$ & & & 3 & 8 & & 2 & 13 & 61.5 \\
\hline$\# 18$ & & 1 & & 10 & & 1 & 12 & 83.3 \\
\hline$\# 12$ & 1 & & & 4 & & 5 & 10 & 50.0 \\
\hline$\# 14$ & & & 1 & 3 & & 6 & 10 & 60.0 \\
\hline$\# 39$ & & 9 & 1 & & & & 10 & 90.0 \\
\hline$\# 57$ & 1 & 7 & 2 & & & & 10 & 70.0 \\
\hline$\# 61$ & 4 & 3 & 2 & & & 1 & 10 & 40.0 \\
\hline Others & 83 & 29 & 103 & 8 & 7 & 26 & 256 & \\
\hline Total & 153 & 118 & 166 & 106 & 101 & 139 & 783 & \\
\hline
\end{tabular}

This table show the result of half-sib families which are constructed by more than 10 offsprings.

* The percentage of the largest cluster (shown in bold) within each half-sib family. 
Table 4. - Summary of three phenotypic traits.

\begin{tabular}{lrrr}
\hline & I Ieight $(\mathrm{m})$ & DBII $(\mathrm{cm})$ & Fork number \\
\hline Mein & 9.19 & 13.18 & 1.38 \\
SD & 2.31 & 3.95 & 0.59 \\
\multirow{2}{*}{ Max } & 14.4 & 26.0 & 3 \\
Min & 1.7 & 2.0 & 1 \\
\hline
\end{tabular}

grouping of offspring into multiple full- and half-sib families with 93 mothers and 153 fathers. Fig. 3 shows the histograms of half-sib family size for both parents. Mothers deduced by the COLONY program disproportionately contributed to offspring in the population, and the contribution per mother ranged between 1 and 104 . On the other hand, the deduced fathers contributed extensively to offspring with different mothers, and the range of contribution per father ranged between 1 and 59. The full-sib family size varied, ranging from 1 to 20 , and the average size was 1.39 (data not shown).

Table 3 compares the results of the STRUCTURE and COLONY analyses. A number of offspring were included in a specific cluster within each half-sib family composed of more than 10 offspring (mean $63.5 \%$, range 40.0-95.9\%). Additionally, some offspring from different half-sib families belonged to the same clusters.

\section{Trait values and estimation of BLUP scores}

Table 4 summarizes the three phenotypic traits examined. The mean values of height, $\mathrm{DBH}$, and fork number were $9.19 \mathrm{~m}, 13.18 \mathrm{~cm}$, and 1.38, respectively. BLUP scores of the three traits (height, $\mathrm{DBH}$, and fork number) were estimated using a linear mixed model with

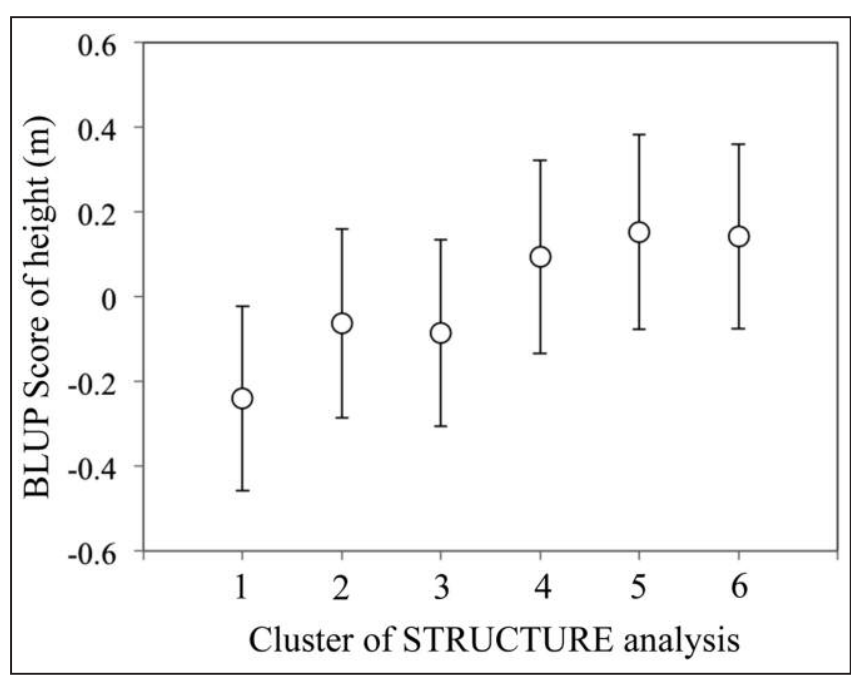

Figure 4. - The BLUP score of height for each cluster. Error bars represent SEs.

spatial residual variance. Table 5 shows log-likelihood and AIC values obtained using two models (STRUCTURE and COLONY) for the three traits with comparison to the null hypothesis of no genetic factors being involved. For height, both models were significantly different from the no genetic factor model based on the likelihood ratio test $(p<0.05)$. The AIC value for height in the STRUCTURE model was lower than the COLONY model. No other traits were significantly different for the two models $(p>0.05)$ and the AIC values for each trait were approximately the same for each model. Fig. 4 shows the BLUP scores of the clusters for height based on the STRUCTURE model. Cluster 5 had the highest BLUP score, and cluster 1 had the lowest.

Table 5. - The log-likelihood and AIC values of two models for the three phenotypic traits compared to the absence of any genetic factors.

\begin{tabular}{lrrr}
\hline & $\begin{array}{l}\text { No genetic } \\
\text { factor }\end{array}$ & \multicolumn{1}{c}{$\begin{array}{l}\text { STRUCTURE } \\
\text { model }\end{array}$} & \multicolumn{1}{l}{$\begin{array}{l}\text { COLONY } \\
\text { model }\end{array}$} \\
\hline Log-likelihood & & & \\
Height & -843.1 & $-839.3^{*}$ & $-840.2^{*}$ \\
DBH & -1693.5 & $-1693.5^{\text {ns }}$ & $-1693.1^{1 \text { 15 }}$ \\
Fork No. & 71.8 & $71.8^{\text {ns }}$ & $71.9^{\text {1s }}$ \\
& & & \\
AIC & & & \\
Height & 1692.2 & 1686.7 & 1688.4 \\
DBH & 3393.0 & 3395.0 & 3394.2 \\
Fork No. & -137.6 & -135.6 & -135.8 \\
\hline
\end{tabular}

Likelihood ratio test; $\mathrm{ns}: \mathrm{p}>0.05,{ }^{*}: \mathrm{p}<0.05$ 


\section{Discussion}

Nine microsatellite markers for T. vernicifluum were developed and characterized. Some of the microsatellites showed high polymorphism, with high heterozygosity and many alleles. As a result, almost all of the individuals genotyped in this study $(98.2 \%)$ could be discriminated using these nine microsatellites. Therefore, these markers will be useful for identifying individuals or clones. Furthermore, they will facilitate such studies as genetic structure analysis and pedigree reconstruction, not only for tree improvement programs, but also for ecological studies of this species.

In this study, the number and the proportionate contribution of parent trees to offspring and the relationships among the parents were unknown. In order to assign genetic groups within the population, we conducted two types of analyses (STRUCTURE and COLONY) using the microsatellite genotype data. In one respect, there was concordance between the two approaches; many members of half-sib families included specific clusters found in STRUCTURE analysis. On the other hand, several differences between the results of the two approaches were also found: both produced different numbers of clusters or half-sib families, half-sib family membership was not restricted to a single cluster, and some clusters included members of more than one half-sib family. There are methodological differences between these two analytical approaches; STRUCTURE is based on providing a group membership posterior probability of individuals using a model-based clustering method, whereas COLONY depends on the exact nature of how parentage and sibships are jointly assigned based on multilocus genotypes. Therefore, obtaining different results from these two approaches is possible. In addition, because of these methodological features and the existence of fewer clusters than half-sib families, the clusters might include several coancestral families.

The result of the STRUCTURE and COLONY models, both which adopt spatial analysis, significant effects of genetic factors for tree height were found, suggest the possibility of backward selection for tree height based on the clusters or half-sib families identified. The AIC value derived from the STRUCTURE model was also lower than those from the COLONY model. Pedigree reconstruction with the COLONY program is calculated more strictly based on multilocus genotypes than the cluster estimation by the STRUCTURE program. On the other hand, the STRUCTURE program would conduct a rougher clustering in which the various genetic backgrounds of each cluster, such as coancestry, are included. The BLUP scores for height of clusters 4, 5, and 6 were higher than clusters 1,2 , and 3 , which were separated into two groups in the first step of STRUCTURE analysis; i.e., individuals with a similar genetic background were similar in height. This result suggests that factors in the genetic background as well as the parentage of individuals affect their growth performance. EL-KASSABY et al. (2011) compared heritability and accuracy of breeding values for combined incomplete (HS) and complete (FS) analysis to both the incom- plete and complete pedigree designs; they demonstrated that HS analysis overestimated the additive genetic variance and underestimated the environmental effects, and the accuracy of parental and offspring breeding values was lower than HS+FS or FS analyses. Based on their results, the STRUCTURE model uses more ambiguous pedigree information than the COLONY model, and this ambiguity might have influenced our estimation of additive genetic variance and the BLUP scores. Thus, results from both the STRUCTURE and COLONY models should be used for ranking the parents of offspring using BLUP scores (equivalent to breeding values if calculated using complete pedigree information) for preventing inclusion of inferior individuals due to estimation error. There were no differences in the loglikelihood or AIC values for $\mathrm{DBH}$ and fork number among clusters or half-sib families. These traits might be influenced primarily by stand conditions such as stand density rather than by genetic factors.

To keep breeding costs to a minimum, it is also desirable to reduce the effort of preparing field experiments. In this study, a commercial plantation for producing lacquer sap was used; therefore, this site did not have an appropriate experimental design (e.g. a random complete block design). Accordingly, it is important to consider introducing other analytical procedures for effective selection based on accurate evaluation of field traits. In such a case, spatial variation removal techniques should be useful (EL-KASSABY and LSTIBU゚REK, 2009). We employed spatial analysis using autoregressive correlations as residual factors for BLUP score estimation, as conducted by DUTKOwsKI et al. (2002). According to these investigators, an autoregressive error structure usually accommodates spatial variation more naturally than designed blocks. Therefore, spatial analysis is a prospective alternative to the traditional random block design methods. Additionally, spatial analysis would allow the use of many existing commercial plantations for evaluation and selection and would reduce the effort required for establishing progeny test trials, thereby leading to low-cost tree improvement.

For the improvement of $T$. vernicifluum, applying the approach reported here for important traits such as quantity and quality of lacquer sap, and resistance to such diseases as white root rot (ТАКЕмото et al., 2012; 2013) should be taken into account as well as growth traits at the study site. We can carry out not only backward selection, but also forward selection using the rank of offspring breeding values based on reconstructed pedigree information; i.e., by selecting superior offspring with better breeding values. In a low-cost improvement framework, seeds obtained by natural mating should be used. Seeds from selected superior female individuals of the population can be collected. Furthermore, other existing populations in afforestation areas consisting of seedlings or clones propagated from roots should be effective for expanding the breeding population of this species.

In summary, this is the first study in which microsatellite markers were developed, genetic groups were classified, and growth traits were evaluated by 
BLUP scores for a $T$. vernicifluum population. Several highly polymorphic microsatellites were developed, and genetic effects based on genetic structure analysis or pedigree reconstruction were detected for tree height, leading to useful information for the improvement of important traits for T. vernicifluum. Additional development of microsatellites or other DNA markers will allow more accurate assessment of the genetic structure or pedigree, leading to a more accurate estimation of BLUP scores and breeding values.

\section{Acknowledgments}

We are grateful to the staff of Forest Tree Breeding Center for assistance in DNA analysis and field investigation. This study was financially supported by the project "Development of sustainable management and production technique for cultivating lacquer trees" as part of parent project 22006, "Research and development projects for application in promoting new policy of agriculture, forestry and fisheries."

\section{References}

AKAIKE, H. (1974): A new look at statistical model identification. IEEE Trans Automat Contr 19: 716-723.

Dutkowski, G. W., J. Costa-Silva, A. R. Gilmour and G. A. LOPEZ (2002): Spatial analysis methods for forest genetic trials. Can J For Res 32: 2201-2214.

El-Kassaby, Y. A., E. P. Cappa, C. Liewlaksaneeyanawin, J. KLÁPŠTĔ, and M. LsTIBŮREK (2011): Breeding without Breeding: Is a Complete Pedigree Necessary for Efficient Breeding? PLOS ONE 6: e25737. doi:10.1371/journal.pone.0025737

EL-KASSABY, Y. A. and M. LstibŮREK (2009): Breeding without breeding. Genet Res 91: 111-120.

Evanno, G., G. Regnaut and J. Goudet (2005): Detecting the number of clusters of individuals using the software STRUCTUTRE: a simulation study. Mol Ecol 14: 2611-2620.

Gilmour, A. R., B. J. Cullis and A. P. Verbyla (1997): Accounting for natural and extraneous variation in the analysis of field experiments. Journal of Agricultural, Biological and Environmental Statistics 2: 269-293.

Gilmour, A. R., B. J. Gogel, B. R. Cullis and R. ThompSON (2009): ASReml User Guide Release 3.0. VSN International Ltd., Hemel Hempstead, HP1 1ES, United Kingdom.

Grattapaglia, D., V. J. Ribeiro and G. D. S. P. Rezende (2004): Retrospective selection of elite parent trees using paternity testing with microsatellite markers: an alternative short term breeding tactic for Eucalyptus. Theor Appl Genet 109: 192-199.

Hamilton, M. B., E. L. Pincus, A. Di Fiore and R. C. FLEISCHER (1999): Universal linker and ligation procedures for construction of genomic DNA libraries enriched for microsatellites. BioTechniques 27: 500-507.

HiraokA, Y. and A. Watanabe (2010): Development and characterization of microsatellites, clone identification and determination of genetic relationships among Rhus succedanea L. individuals. Jour Jap Soc Hol Sci 79: 141-149.

IwATsUKI, K. (1999): Anacardiaceae. In: IwatsuKI, K., D. E. BoufFord and H. OHBA (eds) Flora of Japan, Vol. IIc. Kodansha, Tokyo, pp. 58-59.
Japan Meteorological Agency (2002): Mesh Climate Data 2000 (CD-ROM). Japan Meteorological Business Support Center, Tokyo.

JONES, R. O. and J. WANG (2010): COLONY: a program for parentage and sibship inference from multilocus genotype data. Mol Ecol Res 10: 551-555.

Lambeth, C., B. C. Lee, D. O'Malley and N. Wheeler (2001): Polymix breeding with parental analysis of progeny: an alternative to full-sib breeding and testing. Theor Appl Genet 103: 930-943.

Marshall, T. C., J. Slate, L. E. B. KruUk and J. M. PemBERTON (1998): Statistical confidence for likelihoodbased paternity inference in natural populations. Mol Ecol 7: 639-655.

Miyamoto, M. and A. Kakuda (eds) (2008): An exhibition of Shisui Rokkaku, who established the Japanese 'National Treasure' (in Japanese) [*Title is a tentative translation by authour]. Hiroshima Pref Art Mus, Hiroshima.

Moriguchi, Y., H. Yomogida, H. Iwata, T. TAKahashi, H. TAIRA and Y. Tsumura (2011): Paternity analysis in a progeny test of Cryptomeria japonica revealed adverse effects of pollen contamination from outside seed orchards on morphological traits. Tree Genet Genomes 7: 1089-1097.

PRITChard, J. K., M. Stephens and P. Donnelly (2000): Inference of population structure using multilocus genotype data. Genetics 155: 945-959.

PRITChARD, J. K. and W. WEN (2004): Documentation for structure Software: Version 2. University of Chicago Press. Chicago.

SELF, S. G. and K. LIANG (1987): Asymptotic properties of maximum likelihood estimators and likelihood ratio tests under nonstandard conditions. J Am Stat Assoc 82: 605-610.

SHIRAISHI, S. and A. WATANABE (1995): Identification of chloroplast genome between Pinus densiflora Sieb. et Zucc. and Pinus thunbergii Parl. based on the polymorphism in rbcL gene. J Jap For Soc 77: 429-436. (in Japanese with English summary).

TAKemoto, S., H. NAKAmura and M. TABata (2013): The importance of wild plant species as potential inoculum reservoirs of white root rot disease. For Path DOI: $10.1111 /$ efp.12069.

Takemoto, S., H. Nakamura, M. Tabata, A. Sasaki, Y. ICHIHARA, T. AIKAWA and T. KoIWA (2012): White root rot disease of the lacquer tree Toxicodendron vernicifluum caused by Rosellinia necatrix. J Gen Plant Pathol 78: 77-79.

Untergasser, A., I. Cutcutache, T. Koressaar, J. Ye, B. C. Faircloth, M. Remm and S. G. Rozen (2012): Primer3 - new capabilities and interfaces. Nucleic Acids Res 40: e115.

VÄHÄ, J.-P., J. Erkinaro, E. Niemelä and C. R. Primmer (2007): Life-history and habitat features influence the within-river genetic structure of Atlantic salmon. Mol Ecol 16: 2638-2654.

WANG, J. (2004): Sibship reconstruction from genetic data with typing errors. Genetics 166: 1963-1979.

WANG, J. and A. W. SANTURE (2009): Parentage and sibship inference from multi-locus genotype data under polygamy. Genetics 181: 1579-1594. 